\title{
INCLUSÃO DE ALUNOS COM NECESSIDADES EDUCATIVAS ESPECIAIS: UM ESTUDO DESCRITIVO A PARTIR DOS RELATOS DOS ESTUDANTES
}

\section{ARTIGO ORIGINAL}

SÁ, Ruth Nely Alves de ${ }^{1}$

SALAZAR, Leopoldo Briones ${ }^{2}$

SÁ, Ruth Nely Alves de. SALAZAR, Leopoldo Briones. Inclusão de alunos com necessidades educativas especiais: um estudo descritivo a partir dos relatos dos estudantes. Revista Científica Multidisciplinar Núcleo do Conhecimento. Ano 05, Ed. 11, Vol. 01, pp. 153-167. Novembro de 2020. ISSN: 2448-0959, Link de acesso:

\section{RESUMO}

O presente artigo tem a meta de descrever a realidade da inclusão dos estudantes com necessidades educativas especiais a partir de uma entrevista realizada com três alunos do sexto ao nono ano do ensino fundamental, matriculados na Escola Municipal Elzinha Lizardo Nunes em Alto Taquari no estado do Mato Grosso. O problema fomentador deste estudo partiu da percepção de que há poucas iniciativas de dar voz aos alunos com necessidades educativas especiais ao longo da Educação Básica. Dessa forma, elaborou-se uma entrevista com seis perguntas abertas analisadas a partir da observação direta dos conteúdos coletados. A aplicação se deu em duas etapas, sendo a primeira com a conscientização dos responsáveis pelos menores envolvidos e a segunda com a coleta das informações juntos a esses alunos. Observou-se, com a análise dos dados que ainda há muito a se fazer no processo de

\footnotetext{
${ }^{1}$ Mestre em Ciências da Educação, Especialista em Língua Portuguesa, Literatura e Psicopedagogia.

2 Orientador.
} 
inclusão no que tange ao trabalho desenvolvido pela escola, assim como a atuação da família nesse processo de apoio e acompanhamento. Espera-se, com este trabalho, uma maior oitiva dos maiores interessados no sucesso do processo inclusivo de estudantes com necessidades educativas especiais: os próprios alunos.

Palavras-chave: Inclusão, necessidades educativas especiais, Educação Básica.

\section{INTRODUÇÃO}

Diversos casos de não aprendizagem escolar causam angústia nos membros da comunidade escolar. A maioria não sabe como ajudar efetivamente ou sanar tais problemas, o que, às vezes, possibilita a busca de um maior aprofundamento a respeito das dificuldades da aprendizagem. Na escolas, em sua maioria, as crianças que apresentam problemas de aprendizagem são interpretadas como crianças distraídas, desatentas e/ou preguiçosas. Preocupam-se muito com a inclusão dos deficientes físicos e, por vezes, esquecem as crianças que apresentam distúrbio ou dificuldades de aprendizagem, como: distúrbio do processamento auditivo central, dislexia, dislalia, disgrafia, TDAH (transtorno de déficit de atenção/hiperatividade), entre outros; justificando, assim, estes distúrbios ou dificuldades de aprendizagem como alteração da leitura, escrita e a não interpretação de textos. Tais crianças por sua vez não são incluídas como se deve, mascaram essa inclusão atribuindo um nota fictícia só para não ensinarem de maneira diferente tais alunos, pois isso com certeza dará mais trabalho do que ensinar todos da mesma forma.

A relevância do presente trabalho é descrever a realidade da inclusão dos estudantes com necessidades educativas especiais a partir de uma entrevista realizada com três alunos do sexto ao nono ano do ensino fundamental, matriculados na Escola Municipal Elzinha Lizardo Nunes em Alto Taquari no estado do Mato Grosso.

Sendo assim, a investigação detalhada destas crianças, seguida por um tratamento adequado e uma melhor adequação na sala de aula dos conteúdos a serem apreendidos, poderão mudar radicalmente sua vida escolar bem como o seu desenvolvimento e até sua vida afetiva devida ao aumento de sua autoestima com os 
bons resultados de seus estudos. Na maioria das vezes, estes estudantes não têm distúrbio, dificuldades ou qualquer outra necessidade especial; o que ocorre, em muitos casos, é uma ruptura ou fratura pedagógica no processo de sua alfabetização.

Cabe neste momento, considerar que os estados patológicos se referem principalmente a distúrbios de aprendizagem, em que, segundo Collares e Moysés (1992), há um problema ou uma doença que acomete o aluno em nível individual e orgânico. Já as fraturas pedagógicas, segundo Fernández (1991), são dificuldades de aprendizagem, "resultado da anulação das capacidades e do bloqueamento das possibilidades de aprendizagem de um indivíduo".

Este trabalho tem como foco principal ouvir este público, tendo em vista de que há poucas iniciativas de dar voz aos alunos com necessidades educativas especiais ao longo da Educação Básica. As Leis de inclusão na sua grande maioria tratam dos deficientes físicos, não deixam claro quais sãos os direitos dos alunos que não tem uma deficiência física, mas que também não conseguem aprender como os demais colegas.

Esses alunos têm por muito tempo se apoiado nas Leis de inclusão dos deficientes físicos. Por isso, há de se ampliar as discussões sobre o assunto, aumentando assim, os dados científicos sobre este tema. Diante dos resultados destes dados gerados por pesquisas e discussões a respeito da não aprendizagem de tais alunos, cobrar a quem de direito, leis específicas que garantam os direitos dos mesmos. Sendo assim, este trabalho será voltado à inclusão dos alunos com necessidades educativas especiais focando em alunos com dificuldade na aprendizagem.

Nesse sentido, acredita-se na perspectiva de uma sociedade voltada para a diversidade humana, compreendendo a dinâmica de desenvolvimento de cada sujeito, conhecendo e respeitando as peculiaridades de seu funcionamento na aprendizagem. Para isso, é preciso rever os conceitos em relação à diversidade em sala de aula, evitando rotular e discriminar, evitando julgar os alunos com necessidades educacionais especiais como incapazes. 


\section{UMA BREVE CONCEITUAÇÃO DE DEFICIÊNCIA}

Há muitas formas de se entender a deficiência, algumas antigas, envolvidas por mitos e crenças e outras mais atuais, centradas em pesquisas científicas. Para Jannuzzi (1992), a concepção e sua atribuição são de responsabilidade completa da sociedade, assim também a exclusão dos diferentes, em que seu comportamento foge do esperado. Desse modo, são designados anormais, pessoas que, de certa forma, incomodam a ordem posta.

Geralmente as chamadas classes especiais têm sido ocupadas pelas crianças de camadas mais desfavorecidas, atestando assim muito mais a diferença cultural ou até muitas vezes dificuldades provenientes da própria ineficiência da escola (JANNUZZI, 1992, p. 21).

Diferente da definição fatalista a qual, conforme tunes (2002), pelas chamadas visões sobre naturalistas de caráter divino e naturalista caracterizado pela origem orgânica da deficiência - surge à concepção eussêmica, aceitando a o possível desenvolvimento do indivíduo com necessidades especiais. O termo deficiência é oriundo da língua grega e corresponde às ocorrências favoráveis em uma doença, sendo esta uma definição que é ramificada em visão social e histórico-cultural. Os dicionários, de modo geral, definem o termo como mau funcionamento ou ausência de funcionamento de um órgão; ausência de qualidade ou de quantidade; carência, lacuna ou falta de algo de que se necessita (HOUSSAIS, 2001).

Ainda, segundo Tunes (2002), sob a ótica da visão social, o rótulo de deficiente é atribuído pela sociedade e meio relacional, então, a conceituação é caracterizada pelo papel ou status social adquirido. Há, ainda, o uso pejorativo do termo com o sentido de defeito que uma coisa tem ou perda que experimenta na sua quantidade, qualidade ou valor. Logo, as pessoas são vistas como portadoras de limitações na realização de atividades culturalmente valorizadas e exigidas. Assim sendo, o indivíduo com necessidades especiais é rotulado como incapaz em função das concepções socioculturais e não biológicas. A autora ainda assevera que 
[...] tal defeito não implica, necessariamente, o desenvolvimento de uma deficiência. Apesar de se afigurar como uma dificuldade ou uma barreira para o processo de desenvolvimento comum à maioria das pessoas, ela não é instransponível ou incontornável (TUNES, 2002, p. 11)

Seguindo a visão social da deficiência, Omote (1994) afirma que, sobre essa situação socialmente imposta,

[...] as deficiências não são, do ponto de vista psicológico, diferenças individuais quaisquer. Aquelas que têm, necessariamente, algumas significações de desvantagem e de descrédito social. Portanto, são determinadas diferenças às quais foram atribuídas determinadas significações de desvantagem e que levam os seus portadores a serem desacreditados (OMOTE, 1994 p. 66).

Para visualizar melhor tal definição, basta observar a visão social na definição de deficiência apresentada pela Organização Mundial de Saúde, agência especializada em saúde subordinada à Organização das Nações Unidas a qual atribui o termo para qualquer restrição ou falta de habilidade para executar uma atividade considerada normal para o ser humano (SASSAKI, 1997). Segundo a mesma organização, com dados de 2011, cerca de um bilhão de pessoas vivem com alguma deficiência. Tal retrato significa uma em cada sete pessoas no mundo necessitam de algum tipo de atendimento específico. A falta de estatísticas sobre pessoas com deficiência contribui para a invisibilidade dessas pessoas, representando um obstáculo para planejar e implementar políticas de desenvolvimento que melhoram as vidas das pessoas com deficiência.

Já Vygotsky (1983) ressalta que a concepção estritamente aritmética é um traço típico da defectologia antiga e ultrapassada. Para ele, o ser com defeito não se constitui diretamente um deficiente, isso vai depender do meio social. Assim, um mesmo problema acarreta impactos sociais distintos, conforme o momento e a forma como é interpretado, acreditado e superado.

O efeito do déficit/defeito na personalidade e na constituição psicológica da criança é secundário porque as crianças não sentem diretamente seu estado de handicap. As causas primárias, a sua dita forma especial de desenvolvimento são as limitadas restrições colocadas na criança pela 
sociedade. É a realização sociopsicológica das possibilidades da criança que decide o destino da personalidade, não o déficit em si (VYGOTSKY, 1983, p. 25).

Em consonância a linha adotada por Vygotsky (1983), na qual a limitação é determinada pelos membros da comunidade em que vive o indivíduo com necessidades especiais, Amaral (1994), de acordo com a Organização Mundial de Saúde, separa a deficiência em dois tipos: a deficiência primária e a secundária.

A deficiência primária é caracterizada pelo dano ou anormalidade de estrutura ou função elementar, enquanto a deficiência secundária volta-se culturalmente ao conceito de incapacidade, caracterizaria uma condição de desvantagem, possível apenas em um contexto comparativo, confrontando aquela pessoa ao seu grupo. Para Amaral (1994), mesmo sendo adotadas como irreversíveis, as limitações na deficiência primária não são por si só um impedimento absoluto ao desenvolvimento. O progresso a ser apresentado pela criança com necessidades especiais, depende das possibilidades oferecidas pelo ambiente e suas experiências.

Mazzotta (1998) acrescenta que o indivíduo portador de necessidades especiais é caracterizado por elementos e limitações intrínsecos e extrínsecos, o que exige alterações e adequações do meio para alcançar sua capacidade máxima.

Segundo o autor (1982, p. 43),

a integração social supõe o estabelecimento de relações sociais entre os excepcionais e os demais alunos. [...] Envolve a interação, mediante a comunicação, a assimilação, pela participação ativa e reconhecida do excepcional como elemento do grupo de crianças "normais" e, a aceitação, refletida na aprovação da criança excepcional como elemento participante e aceito no grupo, mediante relações regulares $e$ espontâneas que fazem com que o excepcional sinta-se parte natural do grupo (MAZZOTTA, 1982, p. 43).

Fonseca (1995) relata que, se por um lado há a deficiência, por outro, existem as necessidades educativas e as potencialidades a serem estimuladas para que haja a conquista de uma melhor forma de viver. 
Parece claro que as dificuldades de aprendizagem não são encaradas num modelo interacionista e dialético. Dum lado, os defensores que vêm as dificuldades de aprendizagem na criança e nos seus déficits de processamento da informação. Do outro, os defensores que vêm as dificuldades no professor e nos seus processos de trabalhos. Dislexia ou dispedagogia? Problema da(s) criança(s) ou problema do(s) adulto(s)? Dificuldade de aprendizagem ou dificuldade de ensino? A falta de uma perspectiva integrada, a delimitação de áreas de conteúdo e o divórcio interdisciplinar entre profissionais, fazem perder de vista uma dimensão global das dificuldades de aprendizagem (FONSECA, 1995, pp. 75-76).

Genericamente, segundo Tunes (2002), a deficiência pode compreender a comunicação coletiva, a colaboração e as relações sociais experienciadas com os demais. Uma nova visão de deficiência pode ser apresentada, na qual o caráter fatalista que implica causas divinas, sobrenaturais, orgânicas e hereditárias é deixada de lado e uma visão contextualizada com o meio social passa a vigorar.

Dessa maneira, tem-se que Vygotsky (1983), Amaral (1994), Omote (1994), Mazzotta (1998), Fonseca (1995) e Tunes (2002) já mencionados humanizam a abordagem à deficiência. Esses autores apresentam o indivíduo com necessidades especiais como ser humano, cidadãos, digno dos mesmos direitos dos demais, mas que precisam lidar com os obstáculos impostos pela sociedade. Assim, uma visão diferente é aceita, propiciando que a deficiência deixe de ser um mito e passe a ser uma realidade que tem de ser trabalhada e vivida.

A sensação de inferioridade dos que apresentam necessidades especiais é resultado do condicionamento das relações humanas. Nenhuma diferença é em si vantajosa ou não, são as expectativas do meio social que vão determiná-la. A rejeição ou aceitação ao diferente é que tem o poder de instituir se isso é ou não inadequado, negativo, indesejável e principalmente uma barreira impossível de se ultrapassar e vencer. Assim, embasados em ideias e conceitos historicamente criados, tem-se que a falta de comprometimento com pessoas com necessidades especiais foi o aspecto que determinou a estagnação em uma classe diferenciada, menosprezada e desvalorizada pelos considerados "normais". 
Dessa forma, cria-se o preconceito da deficiência, impedindo ou dificultando uma relação igualitária, reconhecendo o outro como ser humano. Ao contrário disso, há o rótulo, a classificação como incapaz.

\section{CONCEITO DE INCLUSÃO ENQUANTO TERMO EDUCACIONAL}

No modelo atual da inclusão, vários conceitos são revistos tomando outras direções, já que não se podem sustentar mais práticas que ignorem as necessidades específicas daqueles indivíduos que aspiram pela plenitude de seus direitos. Destacase que tal plenitude não foi concretizada pelos indivíduos sem deficiência, mas que aqueles com deficiência no mínimo possam atingir o mesmo nível de acessibilidades aos veículos de informação e conhecimento.

Segundo Sassaki (1997, p 2):

Uma escola comum só se torna inclusiva depois que se reestruturou para atender à diversidade do novo alunado em termos de necessidades especiais (não só as decorrentes de deficiência física, mental, visual, auditiva ou múltipla, como também aquelas resultantes de outras condições atípicas), em termos de estilos e habilidades de aprendizagem dos alunos e em todos os outros requisitos do princípio da inclusão, conforme estabelecido no documento, 'A declaração de Salamanca e o Plano de Ação para Educação de Necessidades Especiais (SASSAKI, 1997, p. 2).

Agora essas pessoas são tidas como portadoras de necessidades educacionais especiais, já que, segundo a Declaração de Salamanca (1994) os governos, de modo geral, devem promover ações que

[...] encorajem e facilitem a participação de pais, comunidades e organizações de pessoas portadoras de deficiências nos processos de planejamento e tomada de decisão concernentes à provisão de serviços para necessidades educacionais especiais (DECLARAÇÃO DE SALAMANCA p. 3).

A definição de Salamanca, no tocante, afirma que escolas regulares que possuam orientação inclusiva constituem os meios mais eficazes de combater atitudes discriminatórias, formando comunidades acolhedoras, construindo uma sociedade

Disponível em:https://www.nucleodoconhecimento.com.br/educacao/necessidades-educativas- 
inclusiva e alcançando educação para todos. Apesar de não se render à complexidade da educação especial em suas contradições e implicações sociais, entende-se que as leis são resultado de todas essas implicações e contradições, que após serem discutidas são elaboradas de forma a assegurar que minimamente os problemas sejam amenizados. A passagem a seguir traz o que se tem de mais importante na Declaração de Salamanca sobre a relevância de se incluir de modo efetivo os que apresentam necessidades especiais na sociedade em geral.

Uma mudança de perspectiva social é imperativa. Por um tempo demasiadamente longo os problemas das pessoas portadoras de deficiências têm sido compostos por uma sociedade que inabilita, que tem prestado mais atenção aos impedimentos do que aos potenciais de tais pessoas (DECLARAÇÃO DE SALAMANCA, 1994).

Dessa forma, quando se pensa em uma sociedade inclusiva tem-se a ideia de que todas as pessoas possuem as mesmas condições e oportunidades de experiencializar todas as situações, fazendo de sua participação um meio participativo e ativo, onde se entenda que as relações individuais sejam estabelecidas a luz de uma igualdade de valores.

\section{CONCEITO DE NECESSIDADE DE EDUCAÇÃO ESPECIAL - NEE}

O termo Necessidades Educacionais Especiais - NEE é aplicado a todas aquelas crianças, jovens ou adultos cujas necessidades educacionais especiais se originam em função de deficiências ou dificuldades de aprendizagem. Segundo Borges (2005),

[...] um aluno tem necessidades educacionais especiais quando apresenta dificuldades maiores que o restante dos alunos da sua idade para aprender o que está sendo previsto no currículo, precisando, assim, de caminhos alternativos para alcançar este aprendizado (BORGES, 2005, p. 03).

O conceito de Necessidades Educacionais Especiais - NEE foi adotado e revisto depois da Declaração de Salamanca (1994), passando a abranger todas as crianças e jovens cujas necessidades envolvam deficiências ou dificuldades de aprendizagem. 
Mazzotta (1996) alerta os profissionais envolvidos e a população em geral

[...] para a inadequação lingüística da expressão "portadores de necessidades educativas especiais, sugerindo que, em lugar dela, usemos "alunos que apresentam necessidades educacionais especiais", o que, sem dúvida, é mais adequado, seja do ponto de vista semântico ou do psicológico (MAZZOTTA, 1996, p. 60).

Desse modo, passou a abranger tanto as crianças em desvantagens como as chamadas sobredotadas, bem como crianças de rua ou em situação de risco, que trabalham, de populações remotas ou nômades, pertencentes a minorias étnicas ou culturais e crianças desfavorecidas ou marginais, bem como as que apresentam problemas de conduta ou de ordem emocional. Outra diferença, no mínimo muito inquietante, foi a inserção da expressão Educação Especial que não constava na versão original da Declaração de Salamanca. Na tradução de 1994, encontra-se a seguinte redação:

A presente Linha de Ação sobre Necessidades Educativas Especiais foi aprovada pela Conferência Mundial sobre Necessidades Educativas Especiais [...]. Seu objetivo é definir a política e inspirar as ações dos governos, de organizações internacionais e nacionais de ajuda, de organizações não-governamentais e de outros organismos na aplicação da Declaração de Salamanca, de princípios, política e prática para as necessidades educativas especiais (DECLARAÇÃO DE SALAMANCA, 1994).

Seguindo a legislação brasileira, segundo a Resolução ํo 2 de 11 de setembro de 2001, que institui as Diretrizes Nacionais para a Educação Especial na Educação Básica (BRASIL, 2001), o atendimento para esse público deve ser realizado de modo personalizado, seguindo os princípios presentesna Declaração de Salamanca (1994).

Art. 60 Para a identificação das necessidades educacionais especiais dos alunos e a tomada de decisões quanto ao atendimento necessário, a escola deve realizar, com assessoramento técnico, avaliação do aluno no processo de ensino e aprendizagem, contando, para tal, com:

I - a experiência de seu corpo docente, seus diretores, coordenadores, orientadores e supervisores educacionais;

II - o setor responsável pela educação especial do respectivo sistema; 
III - a colaboração da família e a cooperação dos serviços de Saúde, Assistência Social, Trabalho, Justiça e Esporte, bem como do Ministério Público, quando necessário (BRASIL, 2001, p.70).

Desse modo, os documentos que visam e regulam a inclusão de alunos os incluem e ao mesmo tempo os excluem, pois o simples fato de separar os direitos de um grupo específico de alunos possibilita a criação de mecanismos independentes e, ao mesmo tempo, excludentes. Muitos dos alunos com necessidades educativas especiais, incluídos/elencados na Declaração de Salamanca, não foram contemplados pelas políticas de Educação Especial, ou seja, foram incluídos em um primeiro momento e excluídos posteriormente.

\section{ENTREVISTA COM ALUNOS DA ESCOLA MUNICIPAL ELZINHA LIZARDO NUNES}

A partir deste ponto, serão analisadas as falas dos alunos selecionados para participarem das entrevistas. Importante lembrar que foram entrevistados três alunos do sexto ao nono ano do ensino fundamental, representando de todos os com necessidades educativas especiais matriculados na Escola Municipal Elzinha Lizardo Nunes.

As perguntas focaram em perceber como os alunos se portavam diante das dificuldades de aprendizagem, comprometimento docente, auxílio docente, respeito, realização de atividades e barreiras no processo.

A primeira pergunta a ser respondida de modo mais analítico pelos alunos versava sobre as dificuldades de aprendizagem, buscando compreender como esses indivíduos regem diante do processo de ensino. A pergunta foi formulada da seguinte forma: Você acha que tem dificuldade para aprender? O quadro a seguir traz as

respostas obtidas após a aplicação da entrevista aos alunos.

Quadro 1. Dificuldades de aprendizagem 


\begin{tabular}{|l|l|}
\hline Aluno I & "Sim, em Matemática”. \\
\hline Aluno II & "Sim um pouco sim, em português e geografia”. \\
\hline Aluno III & "Tenho sim principalmente na aula de matemática”. \\
\hline
\end{tabular}

Fonte: Elaborado para esta investigação.

Todos os entrevistados afirmam que possuem dificuldade para aprender. Essa percepção é o primeiro passo para o avanço destes no processo de ensinoaprendizagem, tendo em vista que negar que o problema existe não 0 faz desaparecer.

Alunos com dificuldades de aprendizagem não podem e nem devem ser comparados aos outros alunos. Portanto, cabe a escola elencar, dentro de seu conteúdo, aquelas habilidades que o estudante com dificuldades em aprendizagem é capaz de desenvolver.

A segunda pergunta a ser respondida pelos alunos questionava o comprometimento docente, buscando compreender como esses indivíduos percebem a atuação do professor. A pergunta foi formulada da seguinte forma: Os professores estão comprometidos com o ensino e se preocupam com o seu aprendizado? O quadro a seguir traz as respostas obtidas após a aplicação da entrevista aos alunos.

Quadro 2. Comprometimento docente

\begin{tabular}{|l|l|}
\hline Aluno I & "Sim". \\
\hline Aluno II & "Sim, alguns sim outros nem tanto". \\
\hline Aluno III & "Eles se preocupam eles me ensinam só que na hora que \\
& passa um pouco eu esqueço". \\
\hline
\end{tabular}

Fonte: Elaborado para esta investigação.

Os alunos relatam que os professores realmente se empenham na tarefa de educar, mas destacam a presença das dificuldades. O Aluno 3 afirma que "Eles se preocupam 
eles me ensinam só que na hora que passa um pouco eu esqueço", revelando a pouca eficácia do processo de ensino realizado na escola.

É de suma importância, também, trazer relembrar o papel da família na superação das dificuldades de aprendizagem, uma vez que o professor e a escola são corresponsáveis por tais superações. Portanto, sem o apoio familiar, o êxito torna-se difícil de ser alcançado pelos alunos com necessidades educacionais especiais ou com dificuldade de aprendizagem.

A terceira pergunta a ser respondida de modo mais detalhado pelos alunos focava no sobre o auxílio docente, buscando compreender como esses indivíduos percebem o apoio do professor. A pergunta foi formulada da seguinte forma: Seus professores circulam na sala de aula, auxiliam os alunos nas atividades individualmente? O quadro a seguir traz as respostas obtidas após a aplicação da entrevista aos alunos.

Quadro 3. Auxílio docente

\begin{tabular}{|l|l|}
\hline Aluno I & "Sim" \\
\hline Aluno II & "Não, todos eles não alguns". \\
\hline Aluno III & "Eles circulam sim". \\
\hline
\end{tabular}

Fonte: Elaborado para esta investigação.

Somente o Aluno 2 respondeu que há professores que não auxiliam nas atividades ministradas, sendo esse um possível indício o preconceito decorrente da hierarquização. Os demais selecionados relatam que são auxiliados e que os docentes circulam na sala.

A quarta pergunta a ser respondida de modo mais analítico pelos alunos versava sobre o respeito, buscando compreender como esses indivíduos percebem essa situação na escola. A pergunta foi formulada da seguinte forma: Você se sente respeitado pelos colegas, professores, coordenadores e diretor? Como eles o/a 
tratam? Percebe algum tipo de preconceito com você em relação a sua dificuldade em aprender?

O quadro a seguir traz as respostas obtidas após a aplicação da entrevista aos alunos.

Quadro 15. Respeito

\begin{tabular}{|l|l|}
\hline Aluno I & "Sim, me tratam bem todo mundo". \\
\hline Aluno II & $\begin{array}{l}\text { "Tem uns que me xinga lá na escola, só os colegas os } \\
\text { professores tratam bem". }\end{array}$ \\
\hline Aluno III & $\begin{array}{l}\text { "Quando eu me sento na sala de aula eles vai em mim } \\
\text { pergunta o que que eu estou sentindo, mas eu sou muito bem } \\
\text { tratada com os professores, diretores todo mundo da escola. } \\
\text { Os colegas me tratam super bem". }\end{array}$ \\
\hline
\end{tabular}

Fonte: Elaborado para esta investigação.

A aluno 2 relata que "Tem uns que me xinga lá na escola, só os colegas os professores tratam bem", sendo este um indicativo de que a escola precisa desenvolver um trabalho que valorize o respeito com os alunos com necessidades educacionais especiais ou com dificuldade de aprendizagem.

A quinta pergunta a ser respondida de modo mais analítico pelos alunos versava sobre realização de atividades, buscando compreender como esses indivíduos percebem lidam com a dificuldade de aprender. A pergunta foi formulada da seguinte forma: Como você se sente quando não consegue desenvolver uma atividade com a mesma facilidade que seus colegas desenvolvem? Você faz algo para mudar isso?

O quadro a seguir traz as respostas obtidas após a aplicação da entrevista aos alunos.

Quadro 16. Realização de atividades
Aluno I
"Fico lá no meu canto quieta". 


\begin{tabular}{|l|l|}
\hline Aluno II & "Muito triste, não". \\
\hline Aluno III & "Eu peço ajuda para o professor quando eu estou com \\
& $\begin{array}{l}\text { dificuldade pra aprender aquela tarefa no mesmo tempo que } \\
\text { eles. Os professores me ajudam sim". }\end{array}$
\end{tabular}

Fonte: Elaborado para esta investigação.

Somente o Aluno 3 ao relatar que "Eu peço ajuda para o professor quando eu estou com dificuldade para aprender aquela tarefa no mesmo tempo que eles. Os professores me ajudam sim" demonstra alguma proatividade diante da situação. Os demais alegam que "Fico lá no meu canto quieta" ou "Muito triste, não", deixando claro que não fazem nada para mudar essa situação. Trabalhos em grupo ou atividades que envolvam cooperação podem auxiliar na inserção e na proatividade desses alunos.

A sexta pergunta a ser respondida de modo mais analítico pelos alunos versava sobre as barreiras no processo, buscando compreender como esses indivíduos percebem lidam com a dificuldade de aprender. A pergunta foi formulada da seguinte forma: Para você quais são as barreiras que impedem que a inclusão dos alunos com dificuldades de aprendizagem aconteça dentro do ambiente escolar?

O quadro a seguir traz as respostas obtidas após a aplicação da entrevista aos alunos.

Quadro 17. Barreiras no processo

\begin{tabular}{|l|l|}
\hline Aluno I & "Não sei”. \\
\hline Aluno II & "Eu não sei não". \\
\hline Aluno III & $\begin{array}{l}\text { "Eu vejo dificuldade quando o professor pede atenção e eles } \\
\text { não prestam atenção aí eu peço pra eles calarem a boca pra } \\
\text { pode aprender o que o professor está querendo ensinar } \\
\text { naquele momento". }\end{array}$ \\
\hline
\end{tabular}

Fonte: Elaborado para esta investigação.

Disponível em:https://www.nucleodoconhecimento.com.br/educacao/necessidades-educativas- 
Somente o Aluno 3 conseguir responder à pergunta proposta afirmando que vê “...dificuldade quando o professor pede atenção e eles não prestam atenção aí eu peço pra eles calarem a boca pra pode aprender o que o professor está querendo ensinar naquele momento." Isso retrata a realidade de um trabalho que precisa de aprimoramentos e planejamento das atividades.

\section{CONCLUSÃO}

Dessa forma, foi possível trazer à tona a realidade dos alunos com necessidades educacionais especiais na Escola Municipal Elzinha Lizardo Nunes em Alto Taquari no estado do Mato Grosso a fim de fornecer um panorama da realidade desses estudantes na Educação Básica. Ainda, espera-se que os governantes direcionem esforços para o melhor atendimento desse público, já que a inclusão de todos é interessante para todos os membros da sociedade.

Assim, um objetivo desafiante para a educação brasileira é a construção de uma escola que possa atender a todos com suas singularidades. Infelizmente, a maior parte das escolas e profissionais da educação não está preparada para lidar com as diferenças no processo de ensino aprendizagem. Por meio da inclusão, acredita-se que aqueles que durante muito tempo estiveram à margem do convívio acadêmico poderão ter seu espaço e atenção adequada direcionada a si. Desse modo, sugerese que os professores atualizem suas práticas pedagógicas.

Portanto, foi muito válida, no presente estudo, a realização de uma pesquisa empírica que, desenvolvida a partir de uma coleta de dados, possibilitou uma compreensão real das dificuldades de aprendizagem na escola, bem como a deficiência de profissionais especializados para colaborar com o trabalho dos professores.

\section{REFERÊNCIAS}

AMARAL, L. A. Pensar a Diferença: Deficiência. Brasília, Editora CORDE, 1994. 
BORGES, José A. As TICs e as tecnologias assistivas na educação de pessoas deficientes, 2005

COLLARES, C. A. L. e MOYSÉS, M. A. A. A História não Contada dos Distúrbios de Aprendizagem. Cadernos CEDES no 28, Campinas: Papirus, 1992, p.31-48.

FERNÁNDEZ. A. A inteligência aprisionada: abordagem psicopedagógica

clínica da criança e da família. Porto Alegre: Artes Médicas, 1991.

FONSECA, V. Educação Especial. 2 ed. Porto Alegre, Editora Artes Médicas, 1995.

HOUAISS, Antônio. Dicionário Houaiss da Língua Portuguesa. Rio de Janeiro, Ed. Objetiva, 2019.

JANUZZI, G. A Luta pela Educação do Deficiente Mental no Brasil. 2 ed. Campinas, Editora Autores Associados, 1992.

MAZZOTTA, M. J. S. Educação Especial no Brasil: Hístória e políticas públicas. São Paulo, Editora Cortez, 1998.

OMOTE, S. Deficiência e Não-Deficiência: Recortes do Mesmo Tecido. Revista Brasileira de Educação Especial, v. 1, ํo. 2, pp. 65-73, jan./jun., 1994.

SASSAKI, R. K. Inclusão: Construindo uma Sociedade para todos. Rio de Janeiro, Editora WVA, 1997.

TUNES, E. Incluir quem, Por que e Para quê? A dimensão ética da inclusão. Goiânia: Anais do XII Encontro Regional de Psicopedagogia, pp. 14-21, 2002.

VYGOTSKY, L. S. Fundamentos de Defectologia. Originalmente publicado em 1983, traduzido por Carmem Pance Fernandez. São Paulo, Editora Martins Fontes, 1995.

Enviado: Setembro, 2020. 
Aprovado: Novembro, 2020. 